Revista de Estudios Histórico-Jurídicos

[Sección historia del derecho europeo]

XLI (Valparaíso, Chile, 2019)

[pp. 235 - 262]

\title{
BERNAT DE OlezA, DOCTOR EN LEYES Y LeCTOR de Volumen Parvum en Bolonia (1398-1400)
}

[Bernat de Oleza, doctor in law and Volumen Parvum lecturer in bologna

(1398-1400)]

\author{
Antonio Planas Rosselló* \\ Universitat de les Illes Balears**
}

RESUMEN

El artículo presenta un esbozo biográfico de Bernardo de Oleza, doctor en leyes por el estudio de Bolonia (1398) y lector de Volumen Parvum en aquel centro entre 1399 y 1400, analizando su papel en la ascensión social de su familia. Se aporta la transcripción de su título doctoral, de su contrato de Lector, y de sendas cartas dirigidas a un mercader de Prato para encargarle la compra de algunos libros y encomendarle la recuperación de otros dados en prenda a su maestro, al doctor Bartolomeo da Saliceto, tras saldar la deuda que había contraído con él.

\section{Palabras clave}

Bernat de Oleza, Estudio de Bolonia, Volumen parvum, Bartolomeo da Saliceto.

\section{Abstract}

The article presents a biographical sketch of Bernardo de Oleza, doctor of law by the University of Bologna (1398) and Volumen Parvum lecturer in that center between 1399 and 1400, analyzing his role in the social ascension of his family. It is provided the transcription of his doctoral diploma, his Lecturer's contract, and two letters directed to a merchant from Prato to order the purchase of some books and to entrust the recovery of others given in pledge to his teacher, Dr. Bartolomeo da Saliceto, after paying off the debt that he had contracted with him.

\section{KEYWORDS}

Bernat de Oleza, University of Bologna, Volumen parvum, Bartolomeo da Saliceto.

RECIBIDO el 11 de mayo de 2019 y ACEPTADO el 2 de julio de 2019

* Profesor Titular de Historia del Derecho. Universidad de las islas Baleares. Facultad de Derecho. IEHM. Edificio Jovellanos, carretera de Valldemossa, km 7'5. Palma de Mallorca. Baleares. España. antonio.planas@uib.es

** Abreviaturas: $A C A .=$ Archivo de la Corona de Aragón. $A D M .=$ Archivo Diocesano de Mallorca. $A G C .=$ Actas del Gran i General Consell. $A H .=$ Archivo Histórico. $A H D E .=$ Anuario de Historia del Derecho Español. ARM. $=$ Archivo del Reino de Mallorca. BSAL. $=$ Bolletí de la Societat Arqueològica Lul.liana. $E O .=$ Extracción de Oficios. $L R$. =Lletres Reials. $M R A M E G H .=$ Memòries de la Reial Acadèmia Mallorquina d'Estudis Genealògics. $R P$. = Reial Patrimoni. SAL. $=$ Societat Arqueològica Lul.liana. 


\section{La familia de Bernat de Oleza (siglos XIII-XIV)}

Bernat de Oleza y Torrebadal, nació en Mallorca a mediados de la década de 1370, hijo legítimo del matrimonio formado por Jaume de Oleza y Martí, ciudadano de Mallorca ${ }^{1}$, y Antonia Torrebadal ${ }^{2}$, hija de una rica familia de mercaderes y banqueros.

En algunos documentos padre e hijo antepusieron el linaje Martí al de Oleza, mediante la fórmula 'Martí alias de Olesa'. Esa particularidad derivaba probablemente de un gravamen de linaje establecido por el ciudadano Pasqual Martí, que nos consta que instituyó heredero a Jaume mediante testamento otorgado el 30 de octubre de $1395^{3}$. El parentesco con el testador derivaba del matrimonio entre Elisenda Martí y Roig ${ }^{4}$, y Jaume de Oleza y Cerdá, abuelos de Bernat.

La grafía del apellido Oleza es variable en los instrumentos medievales: Olesa, Aulesa, Auleza e incluso Euleza en romance, y Olesia, Olegia o Aulesia en latín. Aulesa es la grafía que mejor describe la forma correcta de pronunciarlo en catalán en Mallorca, aunque Olesa es la más usual de escribirlo. En la época moderna se fue consolidando la forma Oleza, que fue fijada por los descendientes de esa familia al inscribirse en el Registro Civil en el siglo XIX. Hemos optado por designar de esa forma al jurista, para resaltar la continuidad histórica del linaje.

El futuro jurista Bernat nació en el seno de una notable familia del patriciado urbano de la ciudad de Mallorca, que se había asentado en la isla poco después de la conquista de $1230^{5}$. Su estirpe provenía de Cataluña y había establecido otra rama en el reino de Valencia ${ }^{6}$, aunque su filiación en el continente no se ha podido perfilar de forma clara y distinta. Durante la primera fase del reinado de Jaime II, uno de sus miembros, llamado Berenguer, ocupó un relevante cargo de la administración insular regia, el de guardián del puerto ${ }^{7}$. En 1285, tras la

${ }^{1}$ ARM., EO., 11, f. 62v; Rosselló Lliteras, Joan, Elspergamins de la Cartoixa de Valldemossa (Palma, 2000), pp. 167 y 174.

${ }^{2}$ Oleza y España, José de, La Familia de Oleza en Mallorca durante setecientos treinta años 1230-1960 (Palma, 1973), p. 30.

${ }^{3}$ En el inventario de bienes de Rafael de Oleza de 1464 figura una copia del testamento (ARM., Prot. 190, f. 169).

${ }^{4}$ Sabemos que dictó su testamento ante el notario Bartomeu Morro el 4 de mayo de 1336 (ARM., Prot. M-190, p. 169), pero no hemos podido consultarlo, ya que no se han conservado sus protocolos.

${ }^{5}$ El 12 de abril de 1240 se documenta a Ramon de Oleza, su esposa Berenguera, y un Berenguer de Oleza, cuyo parentesco con el matrimonio no consta. El primero de ellos poseía el dominio directo de la importante alquería de Bunyolí (Coll Font, Maria Carme, El Llibre Manual de Pere Romeu, notari públic de Mallorca (1239-1243), Tesis Doctoral inédita, UIB, 2012, I, p. 84). Esa alquería se documenta de nuevo como propiedad de Ramón el 7 de abril de 1242 (ADM., Pergamins la parroquia de Sant Jaume, perg. 12).

${ }^{6}$ Montaner, Pedro de, Els origens de l'aristocracia vella mallorquina. Un estat de la qüestió, en Afers, 18 (1994), p. 421.

${ }^{7}$ En 1276 el furor popular asaltó la casa de Berenguer de Oleza, que ocupaba dicho cargo, y destruyó los libros contables donde anotaba los impuestos que le correspondía recaudar (ancoraje, 
deposición del rey Jaime por Alfonso III de Aragón, un Bernat de Oleza prestó juramento de fidelidad al nuevo monarca ${ }^{8}$, y quince años después, el 30 de enero de 1300 , lo renovó a Jaime II de Mallorca, que había recuperado el trono en virtud del tratado de Anagni?.

Desde el siglo XVII diversos historiadores han atribuido a uno de los primeros Oleza, llamado Jaume, haber sido procurador real de Jaime $\mathrm{II}^{10}$, pero no ha sido posible documentar tal afirmación, que creemos debida a un propósito de enaltecimiento de ese linaje. La relevancia del cargo de procurador real habría dejado un importante rastro documental que, en cambio, es inexistente ${ }^{11}$.

En realidad, algunos de los primeros Oleza ocuparon oficios de escribano en la administración del rey. El historiador de la familia, José de Oleza y de España, cita un texto en el que se menciona a Jaime de Oleza como 'Scriptor portionis illustrissimi domini regis Maioricarum', es decir, escribano de la administración patrimonial de la porción del rey en la isla de Mallorca ${ }^{12}$. Un dato que concuerda con las abundantes referencias documentales de un Jaume de Olesa, escribano de ración de la Cancillería de Jaime II -scriptorem nostrum racionalem- que ocupó ese oficio cercano al monarca por lo menos entre 1306 y $1311^{13}$.

Otros historiadores, a partir de Joaquín María Bover, se refieren a un Bernat de Oleza como maestre de la Ceca de Mallorca durante el reinado de Jaime $\mathrm{II}^{14}$, pero no existen fuentes documentales que lo avalen ${ }^{15}$. Pensamos que la afirmación se basa en el hecho de que algunas monedas de ese reinado presentan unos timbres en forma de rosa, análogos al mueble heráldico de los Oleza ${ }^{16}$,

salida de sarracenos, tráfico de mercancías de sarracenos y ventas de los sarracenos) y los gastos que pagaba por el mantenimiento del puerto y su faro. SANTAMARÍA ArÁNDEZ, Álvaro, Ejecutoria del reino de Mallorca 1230-1343 (Palma, 1990), pp. 644-646.

${ }^{8}$ En 1285 uno de los elegidos entre los pobladores del valle de Bunyolí para prestar juramento a Alfonso III fue Bernat de Oleza. Aguiló, Estanislao, Actes de la elecció de Sindichs de la Ciutat $y$ de les parroquies foranes per fer sagrament y homenatge a n'Alfons III de Aragó com a Rey de Mallorca (1285), en BSAL., 9 (1902), p. 67.

${ }^{9}$ En el acto del juramento prestado a Jaime II en 1300 un Bernat Olera (sic) aparece en el elenco de representantes del reino. Mut Calafell, Antoni, Onomàstica dels participants als actes celebrats a Ciutat de Mallorca l'any 1300, en MRAMEGH., 23 (2013), p. 62.

${ }^{10}$ Mut, Vicente, Tomo II de la Historia del Reyno de Mallorca (Mallorca, 1650), p. 326.

${ }^{11}$ Es significativa la total ausencia de acreditación de un Jaume de Oleza que ocupase ese cargo en los estudios dedicados a la institución: ConRado DE Villalonga, José Francisco, La Procuración real en el Reino de Mallorca (Palma, 1991); Sastre Moll, Jaume; Llompart Bibiloni, María, La tesorería del Reino de Mallorca durante su época de esplendor (Palma, 2008).

${ }^{12}$ Oleża y España, José de, La Familia de Oleza, cit. (n. 2), p. 18.

${ }^{13}$ Sevillano Colom, Francisco, De la Cancillería de los Reyes de Mallorca. 1276-1343, en AHDE., 42 (1972), p. 224.

${ }^{14}$ Bover, Joaquín María, Historia de la casa real de Mallorca y noticia de las monedas propias de esta isla (Palma, 1855), pp. 38 y 321; RAmis De Ayreflor Sureda, José, Alistamiento noble de Mallorca del año 1762 (Palma, 1911), p. 192.

${ }^{15} \mathrm{El}$ historiador Álvaro Campaner en una rigurosa monografía publicada en 1879 ya señaló la falta de fundamento de la afirmación de Bover. CAMPANER, Álvaro, Numismática balear (Palma, 1879), p. 119. Tampoco han hallado prueba alguna de ello los especialistas contemporáneos. Orell Jaquotot, Jeroni y Boada Salom, Jaume, Apunts sobre les diverses ubicacions de la seca de Mallorca (segles XIII-XV), en Acta numismática, 43 (2013), pp. 85-93.

${ }^{16}$ En su testamento de 29 de octubre de 1442 el presbítero Pau de Oleza describía las armas 
que se han interpretado como marcas personales de un maestre de esa familia. Sin embargo, tales figuras aparecen asimismo en algunas monedas de épocas posteriores. Miquel de Crusafont ha identificado la rosa como señal del maestre Pere Roig en las del periodo $1343-1348^{17}$.

En el reinado de Jaime III, Jaume de Olesa -probablemente el abuelo de Bernat- prestó servicio a la marina mallorquina en la guerra contra Génova de 1330-1336. Como ha documentado Pablo Cateura, fue comisionado por los jurados del reino para administrar los fondos de la armada, y en virtud de ello le correspondió librar las convocatorias a los enrolados y gestionar el avituallamiento de las naves ${ }^{18}$. Su administración debió resultar conflictiva, pues el 5 de febrero de 1337 el rey ordenó al gobernador de Mallorca que sentenciase un pleito entre Jaume de Oleza y los jurados, de acuerdo con lo actuado por el canciller y sus consejeros en ejercicio de una comisión regia ${ }^{19}$.

Unos años más tarde, el 10 de junio de 1343, el citado Jaume -o quizás ya su hijo- fue uno de los ciudadanos de Mallorca que prestaron personalmente el juramento de fidelidad a Pedro IV de Aragón con homenaje de boca y manos ${ }^{20}$, tras la deposición del rey Jaime.

Desde sus primeras generaciones, los miembros de la familia Oleza pertenecieron al estamento de ciudadanos, un grupo oligárquico ocupado en la administración de sus rentas financieras, inmobiliarias o agrarias y, en muchos casos, al ejercicio de actividades de carácter mercantil. Los ciudadanos gozaban de algunas de las prerrogativas propias del brazo militar, aunque no de sus inmunidades fiscales, que resultaban incompatibles con su facultad para comerciar. Dentro de ese estamento se ubicaban así mismo los juristas, en virtud de sus títulos universitarios, pero los Oleza no se incorporaron a esas profesiones hasta el último tercio del siglo XIV.

En la generación anterior a Bernat, su tío carnal Berenguer de Oleza y Martí, siguió la carrera de leyes. En 1372 era ya in legibus licenciatus $^{21}$, y entre esa fecha y el año 1416 se le documenta ejerciendo la abogacía y ocupando algunos de los cargos públicos que requerían la condición de jurista, como el de asesor del veguer y el de abogado de la universidad del reino ${ }^{22}$. Su hijo, Pau de Oleza, presbítero y beneficiado de la Catedral $(1442 \dagger)$, no cursó estudios universitarios.

así: senyal de rosa blancha ab sis fulles, ab hun punt groch, lo scudet ab camper vermell. DOMENGE Mesquida, J., A laor de Déu e en remissió de pecats. Deixes artístiques en el testament del prevere de Mallorca Pau d'Olesa (1442), en Terés, M. R., Capitula facta et firmata. Inquietuds artístiques en el quatre-cents (Barcelona, 2011), p. 539.

${ }^{17}$ Crusafont i Sabater, Miquel de, Glossari català de Numismàtica, amb totes les poblacions emissores (Països catalans i Corona Catalano-aragonesa) (Barcelona, 2017), p. 368.

${ }^{18}$ Cateura Bennàsser, Pau, El Regne esvaìt: desenvolupament econòmic, subordinació política, expansió fiscal (Mallorca, 1300-1335) (Palma, 1998), p. 60.

${ }^{19}$ ARM., LR., 2, f. 10.

${ }^{20}$ Bofarull, Próspero de, Proceso contra el rey de Mallorca D. Jaime III (Barcelona, 1866), I, p. 446 .

${ }^{21}$ Rosselló Lliteras, Joan, Els pergamins de la Cartoixa, cit. (n. 1), p. 174.

${ }^{22}$ Se le documenta en 1372 como juez delegado (ARM., LR., 28, 76). Fue asesor del veguer en 1374 (ARM., EO., 5, 139v) y 1398 (ARM., AH., 464, 24). En 1393 fue abogado de la Universidad (ARM., $L R$., 41, 17). Documentado por última vez el 27 de junio de 1416, el 5 de marzo de 1418 había fallecido. Rosselló, Joan, Els pergamins de la Cartoixa, cit. (n. 1), pp. 99 y 167. 


\section{Los estudios universitarios de Bernat de Oleza}

Bernat de Oleza, siguiendo los pasos de su tío, decidió cursar los estudios de leyes, animado probablemente por las expectativas de lucro y poder que podían reportarle, y como otros muchos mallorquines -acaso también Berenguer- optó por hacerlo, al menos en su última etapa, en el prestigioso estudio de Bolonia.

$\mathrm{Su}$ elección no fue en modo alguno inusual, pues la presencia de los mallorquines en el estudio boloñés se remontaba a las postrimerías del siglo XIII. Ya en 1300 se han documentado como estudiantes en aquella ciudad los juristas laicos Pere de Vilarasa, Berenguer Fuser y Guillem Ferrer; entre 1320 y 1321 el canónigo de Mallorca y futuro obispo Antoni de Galiana, que cursaba los estudios de leyes; y en 1323 el también canónigo Raimundo de Moncada, hijo de Berenguer, que cursaba los de cánones ${ }^{23}$. Antonio García y García señala que los canónigos fueron el principal colectivo entre los estudiantes de leyes del estudio boloñés ${ }^{24}$. En el caso de los mallorquines, esa asiduidad formativa se vio impulsada por un breve del papa Clemente IV de 13 de diciembre de 1270, que permitió que hubiese permanentemente dos miembros del capítulo catedralicio eximidos de sus obligaciones canónicas durante un quinquenio, para poder seguir estudios universitarios $^{25}$. En la segunda mitad del siglo XIV solo hemos localizado dos graduados laicos mallorquines en Bolonia: el doctor Joan Martí ${ }^{26}$ y el jurista que nos ocupa. Sin embargo, es poco probable que fuesen los únicos en ese periodo. De hecho, Tamburri destaca que la presencia de mallorquines en el Estudio boloñés a lo largo del siglo XIV fue proporcionalmente elevadísima respecto al conjunto de los naturales de la Corona de Aragón y de los hispanos en general ${ }^{27}$. Ello resulta incluso más notable si se tiene en cuenta que algunos mallorquines pueden no haber sido identificados como tales, ya que la documentación boloñesa medieval los caracteriza muchas veces como "catalanus".

Desconocemos donde cursó Bernat los primeros cursos de leyes. No es improbable que peregrinase por varios centros, como sabemos que hicieron muchos otros estudiantes de la Corona de Aragón en general y del reino de Mallorca en particular. Las razones podían ser diversas, aunque en el fondo, ese periplo, como apunta Ramis Barceló, se convertía en "una suerte de grand tour académico que los retoños de las familias nobles y adineradas debían emprender"28.

\footnotetext{
${ }^{23}$ García y García, Antonio, Escolares ibéricos en Bolonia 1300-1330, en Derecho Común en España. Los juristas y sus obras (Murcia, 1991), pp. 21-45; TAMBuRRI BarIaIn, Pascual, Natio Hispanica juristas y estudiantes españoles en Bolonia antes de la fundación del Colegio de España (Bolonia, 1999).

${ }^{24}$ García y GarCía, Antonio, En el entorno del Derecho Común (Madrid, 1999), p. 87.

${ }^{25}$ Neвот, Mateo, El segundo obispo de Mallorca. D. Pedro de Muredine (1266-1282), en BSAL., XIII (1910-1911), pp. 185-186.

${ }^{26}$ Planas Rosselló, Antonio, Relación de juristas mallorquines. Siglo XIV, en MRAMEGH., 6 (1994), p. 63.

${ }^{27}$ Tamburri Bariain, Pascual, España en la Universidad de Bolonia: vida académica y comunidad nacional (siglos XIII-XIV), en Espacio, Tiempo y Forma, Serie III, H. Medieval, 10 (1997), pp. 263-351.

${ }^{28}$ Ramis Barceló, Rafael, Peregrinatio academica: Legistas y canonistas de la Corona de
} 
Tras ocho años de estudio -salvo que se le hubiera dispensado alguno- y por lo menos uno de ellos en aquella ciudad, como disponían los estatutos de $1397^{29}$, Bernat de Oleza, convertido ya en baccalarius ${ }^{30}$, se resolvió a obtener la licenciatura en leyes. Para conseguirlo era necesario que uno o más doctores del estudio boloñés le promoviesen para realizar el examen de grado, tras comprobar que se hallaba en condiciones de superarlo. Los promotores de cada estudiante solían ser aquellos profesores con los que mantenía una relación discipular más estrecha. En su caso, quienes asumieron ese papel fueron los doctores Francesco Ramponi $(1401 \dagger)^{31}$ y Bartolomeo da Saliceto $(1412 \dagger)^{32}$. Con el segundo, el célebre jurista, especialmente celebrado por su valioso comentario a los nueve primeros libros del Código de Justiniano, es con quien Bernat mantuvo un vínculo más particular, según veremos más adelante. Como señala Trombetti, los promotores debían llevar a cabo un minucioso escrutinio -conocido como tentamen - no sólo de los conocimientos sino también de la rectitud moral del estudiante, antes de decidir si debían facultarle para realizar el examen que daba acceso a la licenciatura. En rigor, esta indagación cara a cara tenía que ser la prueba más estricta para alcanzar el grado ${ }^{33}$, aunque no faltaron los casos en los que, por algún género de corrupción, se promovió a personas carentes de los requerimientos necesarios.

Bernat superó satisfactoriamente el reconocimiento intelectual y moral de sus promotores, que lo declararon baccalarius ad privata admisus, condición que le abría la puerta para ser sometido al examen privado - a puerta cerradadel conjunto de los doctores del colegio boloñés. Aun así, para poder acceder efectivamente a la prueba, era preciso que prestase diversos juramentos solemnes y que pagase las tasas correspondientes. Como todos los estudiantes foráneos, Bernat tuvo que prestar un juramento especial que se había impuesto en la universidad para evitar la competencia: no podría enseñar en Bolonia, ni presentar otro candidato al examen de láurea, ni hacer intento alguno para entrar a formar parte del colegio de doctores ${ }^{34}$. Así mismo tuvo que depositar una

Aragón en las Universidades italianas durante el Renacimiento, en Miscellanea Historico Iuridica, 12 (2014), p. 40.

${ }^{29}$ Malagola, Carlo, Statuti delle Università e dei Collegi dello Studio Bolognese (Bolonia, 1888), p. 383.

${ }^{30}$ El baccalarius era el estudiante que, pasados los primeros cursos dejaba de ser un mero oyente para convertirse en un legens o disputans que intervenía activamente en las lecturas y en las disputas universitarias. VERGER, Jacques, Examen privatum, examen publicum: Aux origines médievales de la thése, en Jolly, C. y Neveu, B. (eds.), Elements pour une histoire de la Thése (Paris, 1993), p. 25.

${ }^{31}$ Tiraboschi, Girolamo, Storia della letteratura italiana: Dall'anno 1183 al 1500 (Milán, 1833), II, pp. 342-343; FANTUZZI, Giovanni, Notizie degli Scrittori Bolognesi raccolte da Giovanni Fantuzzi (Bolonia, 1732), pp. 156-162.

${ }^{32}$ Véase entre otros Bartolomeo da Saliceto, en Dizionario Biografico dei giuristi italiani (sec. XII-XX) (Bologna, 2013), I, pp. 185-187.

${ }^{33}$ Trombetti Budriesi, Anna Laura, L'esame di laurea presso lo Studio bolognese. Laureati in diritto civile nel secolo XV, en BRIZZI, Gian Paolo y PINI, Antonio Ivan, Studenti e università degli studenti dal XII al XIX secolo (Bolonia, 1988), p. 156.

${ }^{34}$ Trombetti Budriesi, Anna Laura, Ibíd., p. 159; Bellomo, Manlio, Saggio sull'Università 
cantidad en poder del notario del colegio de doctores, para satisfacer el salario de 20 sueldos boloñeses que percibiría cada uno de los doctores examinantes ${ }^{35}$. Una vez cumplidos estos trámites, pudo personarse ante el archidiácono de Bolonia o su vicario para solicitarle que fijase la fecha de su examen privado.

El día señalado a Bernat para celebrarlo fue el 19 de julio de 1398. Llegado ese momento tuvo que comparecer ante el tribunal, que le asignó el punto o puntos sobre los que versaría la prueba. Lamentablemente el Liber Secretus del Studium bononiensi $^{36}$, donde se registra la noticia de su examen privado, no consigna los puntos que se le asignaron para realizar su ejercicio. Pero, de acuerdo con la costumbre, hubo de tratarse de sendas leyes del Código y del Digesto, sobre las que debería debatir con el tribunal.

Si todo se desarrolló de acuerdo con el procedimiento habitual, una vez asignados los puntos dispuso de unas pocas horas para prepararse, con el consejo de sus promotores. Luego, por la tarde, tuvo que comparecer de nuevo para someterse a las preguntas y objeciones que los doctores presentes le plantearon sobre el asunto.

En el diploma de su título doctoral -que hemos localizado y transcribimos en el apéndice ${ }^{37}$ - sólo se indica, con un habitual formulismo, que desarrolló la prueba legendo, repetendo, arguendo, argumenta ipsorum doctorum reassumenda et ea viriliter solvendo, y que fue finalmente aprobado nemine discrepante. Esa era la máxima calificación, ya que para superar el examen era suficiente contar con la mayoría simple de votos positivos ${ }^{38}$. Aunque era muy frecuente que se consiguiese la unanimidad, no siempre el estudiante se libraba del 'reprobo' de algunos de los doctores. Jacques Verger afirma que no se conoce ningún caso en que el estudiante, pasado el tentamen o examen secretus, suspendiese el examen privado, tal vez porque tales reveses no se registraban en los libros de las universidades ${ }^{39}$.

Según se informa en el diploma, intervinieron en el desarrollo de este ejercicio, en presencia de sus dos promotores, los otros catorce doctores numerarios que en ese momento integraban el colegio: Andrea de Bobus, prior, Ugolino Scappi $(1405 \dagger)^{40}$, Nicoló de Zappolino ${ }^{41}$, Ugolino Preti o dei Presbiteri $(1412 \dagger)^{42}$,

nell'età del diritto comune (Roma, 1992), pp. 238-239.

${ }^{35}$ Malagola, Carlo, Statuti delle Università, cit. (n. 29), p. 387.

${ }^{36}$ Die xviii Julii. Dominus Bernardus de Catelonia, presentatus privato examini Iuris Civilis per famosissimos legum doctores dominum Franciscum de Ramponibus et dominum Bartholomeum de Saliceto. Sorbelli, Albano, Il "Liber secretus iuris Caesarei" dell'Università di Bologna, I, 13781420, (Bolonia, 1938), p. 121.

${ }^{37}$ Archivo de Can Ribas de Pina, Fondo Desmur, perg. 1. Apéndice, doc. 1. Debemos su localización y consulta a la gentileza de su propietario, D. Manuel Oliver Moragues.

${ }^{38}$ TrombetTi Budriesi, Anna Laura, cit. (n. 33), p. 160.

${ }^{39}$ Verger, Jacques, Examen privatum, examen publicum, cit. (n. 30), p. 42.

${ }^{40}$ Mazetтi, Serafino, Repertorio di tutti i Professori antichi e moderni della famosa Università e del celebre istituto delle scienze di Bologna (Bologna, 1848), p. 286.

${ }^{41}$ Ibíd., pp. 223-224.

${ }^{42}$ Ibíd., p. 255. 
Tomasso da Sant Giovanni $(1421 \dagger)^{43}$, Giovanni da Lapi $(1401 \dagger)^{44}$, Geremia de Angelelli $(1417 \dagger)^{45}$, Giovanni da Canitulo o Canetoli $(1407 \dagger)^{46}$, Carlo da Zambecari ${ }^{47}$, Nicoló da Aldrovandi ${ }^{48}$, Nicoló da Azzoguidi $(1416 \dagger)^{49}$, Bente da Bentevogli ${ }^{50}$, Giovanni da Santagata ${ }^{51}$ y Floriano da Sampieri ${ }^{52}$. Sin embargo, el Liber Secretus refiere que solamente fueron trece los presentes ${ }^{53}$, sin que podamos saber cuál de los citados en realidad no acudió.

Tras la obtención de la licenciatura, a través del examen privado, la promoción al grado de doctor no presentaba dificultades de carácter intelectual o académico, sino solamente financieras, ya que requería un cuantioso desembolso ${ }^{54}$. Por esa razón, algunos licenciados se conformaban con aquel título, que les facultaba para la mayor parte de sus posibles actividades profesionales en el foro. Probablemente ese fue el caso de su tío Berenguer, que abandonó sus estudios siendo licenciatus in legibus. Sin embargo, Bernat se determinó a culminar su carrera con la láurea doctoral que, como señala Bellomo, propiciaba un ascenso social o, cuando menos, la consolidación de una categoría ya alcanzada ${ }^{55}$.

Por fin, cumplidos los trámites pertinentes, el 9 de septiembre de 1398 tuvo lugar en la catedral de San Pedro de Bolonia la ceremonia pública y solemne de la colación de su grado de doctor ${ }^{56}$. Fue solo dos meses después de su licenciatura, algo habitual ya que el doctorado raras veces se demoraba mucho desde la obtención de aquel grado. En el siglo XV fue frecuente que ambas pruebas se realizaran el mismo día.

El acto público debía ser presidido por el archidiácono de Bolonia, a quien desde la promulgación de la bula de Honorio III de 28 de junio de 1219, y de acuerdo con los estatutos vigentes, correspondía conferir la licentia docendi. Sin embargo, como se indica en el título, en esa ocasión ocupó su lugar el licenciado en cánones Jerónimo de Polonia, lector de Decreto en aquel estudio en $1397^{57}$, con autoridad delegada por el canonista Gaspar de Calderinis $(1399 \dagger)^{58}$, doctor en ambos derechos, conde palatino y caballero boloñés, que era el vicario

\footnotetext{
${ }^{43}$ Ibíd., p. 306.

${ }^{44}$ Ibíd., p. 178.

${ }^{45}$ Ibíd., p. 24.

${ }^{46}$ Ibíd., p. 81.

${ }^{47}$ Ibíd., p. 326.

${ }^{48}$ Ibíd., p. 18.

${ }^{49}$ Ibíd., p. 33.

${ }^{50}$ Ibíd., p. 48.

${ }^{51}$ Giovanni Cattani, di Sant'Agata. Ibíd., p. 90.

${ }^{52}$ Ibíd., p. 279.

${ }^{53}$ Interfuerunt, ultra presentantes, tredecim numero. Fuit aprobatus ab omnibus, nemine discrepante. Sorbelli, Albano, Il "Liber secretus, I, cit. (n. 36), p. 121.

${ }^{54}$ Brundage, James A., The medieval origins of legal profession. Canonists, civilians and courts (Chicago, 2008), p. 260.

${ }^{55}$ Bellomo, Manlio, Saggio sull'Università, cit. (n. 34), p. 225.

${ }^{56}$ Sorbelli, Albano, Il "Liber secretus, I, cit. (n. 36), p. 124.

${ }^{57}$ Dallari, Umberto, I rotuli dei lettori legisti e artisti dello studio Bolognese dal 1384 al 1799 (Bolonia, 1924), IV, p. 21.

${ }^{58}$ Mazetti, Serafino, Repertorio di tutti i Professori, cit. (n. 40), p. 76.
} 
designado por el archidiácono, a la sazón Baltasar Cossa de Nápoles -el futuro antipapa Juan XXIII- que se hallaba ausente de aquella sede, in remotis agentis.

Asistieron al acto los dieciséis doctores que habían participado en el examen privado, así como los obispos Nicolás de Corbia, Juan de Dragonaria y Pino de Sirmio, el célebre canonista Pietro d'Ancarano $(1416 \dagger)^{59}$, iuris utriusque doctor, a quien se menciona expresamente, y una copiosa multitud integrada por profesores, escolares, eclesiásticos, religiosos y otras muchas personas de condiciones diversas.

De acuerdo con lo establecido, Bernat debió pronunciar el sermo promotionalis, un discurso solemne sobre el Ius Civile, e impartir luego una breve lección de tema libre, a modo de praelectio. A continuación, Jerónimo de Polonia, en sustitución del archidiácono, se hizo cargo del sermo archidiaconalis, un parlamento más o menos pautado, en el que se incluían referencias a las cualidades y condiciones del doctorando ${ }^{60}$. Una vez cumplidos esos actos, se dio paso a la ceremonia de imposición de las insignias doctorales. En el título se refiere que le fueron impuestas por sus promotores: Francesco Ramponi le entregó el libro, que fue abierto y cerrado, y Bartolomeo de Saliceto le impuso el anillo y el birrete. Ambas acciones rituales, como era costumbre, fueron precedidas por el beso de paz y la bendición magistral. A través de este ceremonial se le confirió la autoridad doctoral que implicaba la licencia para ejercer públicamente sus atribuciones, en Bolonia y cualquier otro lugar (quoslibet actus in ipso Iure, publice exercendi Bononie et ubique locorum).

\section{El lectorado de Bernat de Oleza. Algunas vicisitudes boloñesas}

Tras la obtención del doctorado Bernardo permaneció en Bolonia donde, según parece, sustituyó temporalmente a su maestro, Bartolomeo da Saliceto, en el ejercicio de su docencia.

Un año más tarde, el 30 de diciembre de 1399, fue contratado para leer en la facultad de leyes durante un año ${ }^{61}$. Su nombramiento para ese menester fue fruto de la elección practicada por la Universitatem dominorum scolarium Utriusque Iuris Studii Bononiensis, es decir, por una comisión constituida por los dos rectores y 38 estudiantes, 19 citramontanos y 19 ultramontanos ${ }^{62}$, y confirmada por las autoridades académicas: los Reformadores del Estudio y los magníficos Ancianos o magistrados municipales de Bolonia.

En el contrato le fue encomendada la lectura del Volumen, con un salario de 100 libras boloñesas, que le debía pagar el municipio. Como tal aparece en el rótulo del Studium bononienis de 1398-1399, junto con otros cuatro profesores de la misma materia: los boloñeses Ugolino da Rizzoli, que se había graduado

\footnotetext{
${ }^{59}$ Ibíd., p. 23.

${ }^{60}$ Trombetti Budriesi, Anna Laura, cit. (n. 33), pp. 162-163.

${ }^{61}$ Archivo de Can Ribas de Pina, Fondo Desmur, perg. 2. Apéndice, doc. 2. Debemos su localización y consulta a la gentileza de su propietario, D. Manuel Oliver Moragues.

${ }^{62}$ Bellomo, Manlio, Saggio sull'Università, cit. (n. 34), p. 202.
} 
en leyes en agosto de $1398^{63}$, Giovanni Conforti ${ }^{64}$, Brau da Reni, laureado en $1397^{65}$, y Giovanni da Scanello, laureado en $1392^{66}$. En el caso de Oleza, a diferencia de los otros, se dice que es legum doctor y electus per universitatem ${ }^{67}$. En el rótulo no se le adjudica un adjetivo gentilicio, lo que explica que no fuese detectado por Antonio Pérez Martín en su elenco de profesores hispanos.

Como indica dicho autor, los lectores elegidos por la Universidad percibían salario por sus clases, y debían ser estudiantes aventajados, no ser boloñeses, haber estudiado al menos un año en aquel estudio, contar al menos con 21 años, y ser pobres. Tenían la obligación de licenciarse y doctorarse en el plazo de un año ${ }^{68}$. Pero en el caso de Bernat de Oleza, cuando fue elegido lector era ya legum doctor, como se indica expresamente en el rótulo, tal vez porque ello constituía un hecho excepcional que debía ser reseñado.

La materia sobre la que tuvo que impartir su docencia fue el Volumen o Volumen parvum, el último de los cinco libros que integraban el Corpus Iuris Civilis, según su división medieval, en el que se reunían el Autenticum (una colección de Novelas justinianeas o Novae leges), los tres últimos libros del Código de Justiniano (Tres libri), la Instituta, y los Libri Feudorum milaneses. El Volumen era considerado de importancia secundaria para la formación de los juristas y, por tanto, su lectura tenía el carácter de extraordinaria. Por ello, su docencia se impartía por las tardes, y se asignaba a los profesores con menor experiencia y prestigio, como fue el caso de Bernat de Oleza, recién doctorado.

Bernat de Oleza no sería el único mallorquín en desempeñar la docencia en aquel Estudio. Unos años más tarde, el canonista Arnau de Marí, alias de Santacília, impartió la lectura extraordinaria del Decretum en 1417-1418 y la extraordinaria del Sexto y las Clementinas el curso siguiente, siendo, como Bernat de Oleza, electus per Universitatem. Tras esta experiencia, continuó allí su trayectoria eclesiástica durante algún tiempo. ${ }^{69}$ Una vez regresado a la isla fue vicario general del obispo Lluis de Prades (1407-1429) y culminó su carrera ocupando la silla episcopal mallorquina entre 1460 y su muerte en 1464, a los 85 años según informa su lauda sepulcral de la catedral de Mallorca ${ }^{70}$. Contaba 38 años cuando accedió a la plaza de lector, una edad avanzada para tal menester. No consta que después de él existiesen nuevos lectores mallorquines. Los hubo, sin embargo, de origen hispánico, muchos de ellos procedentes de otros territorios de la Corona de Aragón, que han sido identificados por Antonio Pérez Martín.

No es mucho lo que sabemos acerca de la vida de Bernat en aquellos años estudiantiles. Los archivos toscanos conservan muchas trazas de los estudiantes mallorquines en Pisa o Florencia, a los que vemos agrupados en la cofradía

\footnotetext{
${ }^{63}$ Mazetti, Serafino, Repertorio di tutti i Professori, cit. (n. 40), p. 267.

${ }^{64}$ Ibíd., p. 98.

${ }^{65}$ Ibíd., p. 262.

${ }^{66}$ Ibíd., p. 155.

${ }^{67}$ Dallari, U., I rotuli dei lettori legisti e artista, cit. (n. 57), p. 25.

${ }^{68}$ Pérez Martín, A., Españoles en el Alma Mater Studiorum (Murcia, 1999), p. 16.

${ }^{69}$ Ibíd., pp. 45-46.

${ }^{70}$ Llompart, Gabriel, La población medieval del subsuelo de la Catedral, en PASCUAL, A., La Catedral de Mallorca (Palma, 1995), p. 84.
} 
de Santa Úrsula, compartiendo casas en alquiler o subarriendo, participando en carnavales y pendencias estudiantiles, o atravesando serias dificultades económicas $^{71}$. En cambio, los cartularios boloñeses apenas nos han dado luz sobre las vicisitudes por las que pasó Bernat, que debieron ser muy parecidas. Nos consta, eso sí, que no fue colegial de San Clemente de los Españoles -como no lo fue ninguno de los mallorquines que estudiaron en aquella ciudad ${ }^{72}-y$ que, por tanto, tuvo que resolver por otros medios el problema de su alojamiento y manutención. Así mismo, como casi todo estudiante ultramontano, se vio en la necesidad de acudir al crédito a fin de cubrir sus gastos y, para ello, recurrió a su maestro Bartolomé de Saliceto.

Que los estudiantes recurriesen a los préstamos de sus profesores no era en absoluto infrecuente. De hecho, Bellomo refiere que algunos de ellos actuaron como verdaderos usureros con sus discípulos: Accursio y Odofredo tuvieron esa fama en el siglo XIII. Por lo general, careciendo de otros bienes de valor, los estudiantes dejaban en prenda sus libros para garantizar esos préstamos dinerarios $^{73}$. Ese fue exactamente el caso de Bernat de Oleza, quien para solventar sus necesidades crediticias acudió a su maestro Saliceto y le depositó como caución algunos libros. Concretamente, los manuscritos pignorados fueron unos quinternos que contenían la Lectura del propio Saliceto sobre el libro IX del Código y sobre el libro IV, desde la ley Sciens del título ad Senatus consultum Veleyanum (C. IV, 29, 7) hasta el final (IV, 41, 2), que había hecho escribir para él en Bolonia, y otros dos quinternos de forma mayor, que incluían la Repetitio sobre la ley edita C. de Edendo (C, II, 1, 3), de Baldo degli Ubaldi (1327-1400) y el tratado De reprobatione testium de Bartolo de Sassoferrato (1313-1357). Por último, un quinterno escrito de su propia mano en el que transcribió una Repetitio impartida por Saliceto en Bolonia, y un libro formado por él mismo con folios de pergamino, que contenía un Tractatus de Iurisdictione, otro sobre materia de la Trinidad, y otras obras.

En 1403, tiempo después de su regreso a Mallorca, Bernat se puso en contacto con el mercader Cristofano di Bartolo Carocci, que dirigía en la isla una compañía financiera y mercantil asociada a la casa Datini de Prato, para encargarle que recuperase sus libros pignorados a cambio de entregar a su maestro una cantidad y compensarle con la remuneración que le correspondía por haberle sustituido temporalmente en la impartición de algunas lecciones. Para llevar a cabo dichas gestiones, le encomendó que se pusiese en contacto con un mercader de Prato llamado Cinolo de Guardinis o, en caso de que hubiera fallecido, con su hermano o su cuñado. La cantidad en la que cifraba Bernat el precio para recuperar sus libros ascendía, más o menos, a 10 ducados o florines de Florencia, y la cantidad a compensar era de 50 libras boloñesas.

${ }^{71}$ Planas Rosselló, Antonio, Los estudiantes mallorquines en Italia y el Humanismo jurídico, en Al tombant de l'edat mitjana. Tradició medieval i cultura humanista (Palma, 2000), pp. 469-482.

${ }^{72}$ Así se puede comprobar en el exhaustivo estudio de Pérez Martín, Antonio, Proles Aegidiana (Studia Albornotiana XXXI, Roma-Madrid, 1979).

${ }^{73}$ Bellomo, Manlio, Saggio sull'Università, cit. (n. 34), p. 99. 
Pero su interés por disponer de libros profesionales no se limitó a recuperar aquellos que había pignorado. En agosto de 1401, estando ya en Mallorca, había adquirido un Liber sextus - las Decretales de Bonifacio VIII- con glosa, en la subasta de la biblioteca de Joan de Vilanova, sacrista de la iglesia de Santa Eulàlia ${ }^{74}$. Y dos años después, además de las citadas gestiones, encomendó a Cristofano di Bartolo Carocci que a través de su socio en Bolonia le proporcionase una lectura de Cino de Pistoia (1270-1336) y la Lectura de Bartolo de Sassoferrato sobre el Código de Justiniano, para sí mismo, y la Lectura del propio Bartolo sobre el Digestum Novum, debidamente miniada, por encargo del jurista catalán Gabriel Cardona, in legibus licenciatus, que a la sazón ocupaba el cargo de asesor del gobernador o lugarteniente real de Mallorca ${ }^{75}$. Tales libros le debían ser entregados por el licenciado (o todavía estudiante) en leyes Pere Sa Bisbal ${ }^{76}$, y en caso de que se hallase ausente de Bolonia, debía hacer el pago a Martín Martí de Torres, un estudiante catalán que moraba en el colegio de los españoles de aquella ciudad ${ }^{77}$.

Conocemos esas contingencias a través de sendas cartas conservadas en el Archivo de Prato, en el rico fondo del mercader Francesco di Marco Datini (1335-1410), dirigidas por Bernat de Oleza al citado Carocci Cristofano di Bartolo di Cenni da Barberino di Mugello. Ezio Levi ya había dado sucinta noticia de una de esas $\operatorname{cartas}^{78}$, que ahora hemos podido transcribir ${ }^{79}$.

\section{El Regreso a Mallorca. Actividad profesional y política}

Como la mayoría de los estudiantes ultramontanos del estudio boloñés, especialmente los laicos, Bernat regresó a su tierra natal con la intención de ejercer las facultades derivadas de su titulación: iudicare, consulere et advocare. Los títulos conferidos por las universidades medievales concedían la licencia para

${ }^{74}$ Hillgarth, J. N., Readers and books in Majorca. 1229-1550 (Paris, 1991), p. 459.

${ }^{75}$ Gabriel Cardona fue Asesor interino del gobernador de Mallorca durante la suspensión del titular Jaume de Viladesters entre 1395 (ARM., LR., 42, 327) y el 27 de mayo de 1396 (ARM., RP., 36, 24). El 31 de mayo de 1396 por mandato del rey Martín I fue preso junto con otros consejeros de Juan I para someterles a proceso, por estar infamados de ser autores de grandes abusos (Mitjà, Marina, Procés contra els consellers domèstics i curials de Joan I, entre ells Bernat Metge, en BRABLB., 27 (1958), p. 400). Sin embargo, debió salir indemne del proceso pues ejerció de nuevo el cargo de asesor del gobernador de Mallorca con carácter interino entre 1400 (ARM., LR., 45, 91) y 1406 (LR., 46, 20). En 1407 Martín I le autorizó a designar un sustituto en el cargo de asesor del gobernador, pues debía desplazarse a Cataluña (LR 46, 243).

${ }^{76}$ Pensamos que se puede identificar con un "Petrus catalanus", que se licenció en leyes en Bolonia el 25 de agosto de 1403 y se doctoró el 13 de septiembre siguiente. Sorbelli, Albano, Il "Liber secretus, I, cit. (n. 36), pp. 158-159.

${ }^{77}$ Pensamos que se puede identificar con un Martinus de Valentia, colegial entre 1401 y 1410, que fue rector en 1404. Pérez Martín, Antonio, Proles Aegidiana, cit. (n. 72), I, p. 184. El hecho de que se refiera a él como "catalanus", podría ser por el mismo motivo lingüístico por el que en Bolonia se denominaba así a los mallorquines.

${ }^{78}$ LEVI, Ezio, El romance florentino de Jaume de Olesa, en Motivos hispánicos (Florencia, 1933), pp. 44-45.

${ }^{79}$ Apéndice, documentos 3 y 4 . 
enseñar derecho, fuese en el propio centro -la licentia docendi- o en cualquier universidad, la licentia ubique docendi que era prerrogativa propia del doctorado. Pero las normativas de la mayor parte de los reinos en los que se había recibido el Ius Commune exigían así mismo aquellos títulos universitarios para patrocinar a las partes en los litigios y para juzgar los pleitos, fuese directamente o como asesores togados de un juez lego.

Aunque la dirección letrada de las partes litigiosas no era obligatoria en Mallorca en aquella época, quienes carecían de la titulación adecuada podían ejercer su patrocinio puntualmente, pero no hacer de ello su modus vivendi. La pragmática del virrey Hugo de Anglesola de 31 de julio de 1398 había exigido una rigurosa formación jurídica para el ejercicio de la abogacía. De acuerdo con ella, se requería ser doctor, licenciado, o aprobado en leyes o cánones o, en su defecto, haber estudiado derecho durante cinco años en un estudio general, y haber pasado un examen ante dos juristas elegidos por el gobernador, en presencia de éste y de los jurados del reino ${ }^{80}$. La permanencia en un estudio durante el tiempo fijado se debía acreditar mediante certificados expedidos por aquellos centros. Ese plazo quinquenal, que era el señalado por Azzo de Bolonia en su Summa Codicis ${ }^{81}$, se había impuesto desde antiguo en algunas ciudades, como Módena en 1328, Barcelona en $1335^{82}$, o Florencia en $1340^{83}$.

La citada pragmática exigió también a los juristas que quisieran ejercer en la isla que estuviesen en posesión de los libros ordinarios de aquel derecho que hubiesen oído, fuese civil o canónico. Así que la preocupación de Bernat por recuperar sus empeñados manuscritos y adquirir las Lecturas del Código y el Digesto, respondía a un claro interés profesional. Fuese o no obligatorio disponer de ellos, los libros resultaban imprescindibles para practicar sus cometidos en las debidas condiciones, de tal manera que, por ejemplo, en Cataluña se consideraban bienes inembargables, como las herramientas necesarias para el desempeño de cualquier otro oficio. ${ }^{84}$

Tras su regreso, el flamante legum doctor se dedicó desde un primer momento al lucrativo ejercicio de la abogacía. En agosto de 1432, en un procedimiento seguido ante la curia del gobernador para verificar el uso judicial que hacía prevalecer en los juicios la opinión mayoritaria de los prohombres legos sobre la del juez letrado, Bernat testificó que lo había visto aplicar sin contradicción alguna desde 32 años atrás ${ }^{85}$. Ese testimonio indica que había iniciado su práctica

${ }^{80}$ Pons Pastor, Antoni, Constitucions e ordinacions del Regne de Mallorca (S.XIII-XV) (Palma, 1934), II, p. 170.

${ }^{81}$ Gouron, André, Le rôle de l'avocat selon la doctrine romaniste, en Recueils de la Société Jean Bodin pour l'histoire comparative des institutions, 65 (1998), p. 18.

${ }^{82}$ Montagut Estragués, Tomás de, El régimen juridico de los juristas de Barcelona en la Baja Edad Media, en Rudimentos legales: Revista de Historia del Derecho, 2 (2000), pp. 78-79.

${ }^{83}$ Martines, Lauro S., Lawyers and statecraft in medieval Florence (Princeton, 1968), pp. 31-33.

${ }^{84}$ Ferro, Víctor, El Dret públic català. Les institucions a Catalunya fins al Decret de Nova Planta (Barcelona, 1987), p. 391.

${ }^{85}$ ARM., Suplicacions, 35, f. 2. Planas Rosselló, Antonio, La participación popular en la Administración de Justicia del Reino de Mallorca, en AHDE., 66 (1996), p. 179. 
profesional ante las curias mallorquinas entre 1400 y 1401, recién finalizado su contrato de lector en Bolonia.

Sabemos que en su casa y estudio le sirvió como escudero durante siete años el futuro doctor en leyes Martí Desbrull ${ }^{86}$, que debió iniciarse así en los vericuetos de la abogacía, y más tarde un personaje llamado Domingo Pascual ${ }^{87}$. También residió bajo su techo el causídico Joan Aja, procurador ad litem que estuvo a su servicio durante más de 20 años $^{88}$. En su práctica profesional, mantuvo un acuerdo con el notario Jaume Barber ${ }^{89}$, a quien prestaba gratuitamente sus servicios como abogado a cambio de los trabajos que le encargaba como fedatario ${ }^{90}$. Respecto a su clientela, sólo hemos podido averiguar que fue abogado del ciudadano Ponç Descós ${ }^{91}$, y que en 1416 prestaba su patrocinio al Colegio de Monederos, la corporación que agrupaba a los privilegiados oficiales de la Ceca de Mallorca $^{92}$. Lamentablemente, la pérdida de los protocolos de Jaume Barber nos ha privado de una fuente inestimable para conocer su actividad profesional con mayor detalle. El asesoramiento y la negociación jurídica extrajudicial era la labor más lucrativa de un jurista ${ }^{93}$, y para ello a menudo se convenía con el cliente un salario fijo a través de un contrato autorizado por notario.

En aquella época eran escasos los juristas ejercientes en la isla. En 1447, cuando se llevó a cabo la primera insaculación para elegir mediante sorteo cuatro de los oficios reales o municipales reservados a los letrados (los de asesor del batle, del veguer de la ciudad y del veguer foráneo, y el de abogado de la universidad del reino), se incluyeron solamente 18 . Un número reducido para una sociedad no poco litigiosa como era la mallorquina, y que permitía asegurarse una buena cartera de clientes.

Simultáneamente al libre ejercicio de la profesión, Bernat de Oleza ocupó algunos de los cargos judiciales de mandato anual: fue asesor del batle de Mallorca en 1408 y $1413^{94}$, y del veguer foráneo en $1427^{95}$. En esas fechas tales empleos eran designados por el monarca o, más frecuentemente, por su lugarteniente en Mallorca, aunque debían contar con la aprobación de los magistrados regnícolas ${ }^{96}$. En junio de 1424 fue nombrado asesor del veguer en todas las causas en las que fuera parte el doctor Vicenç Salzet, por su manifiesta enemistad con el titular del cargo, el doctor Joan Armadans ${ }^{97}$. Así mismo, en 1431 ejerció la lugartenencia del

${ }^{86}$ SAL., Fondo Aguiló, Ms. 57, ff. 35-36.

${ }^{87}$ Ibíd., f. $22 \mathrm{v}$.

${ }^{88}$ Ibíd., f. 32.

${ }^{89}$ Planas Rosselló, Antonio, Los notarios mallorquines del siglo XIV, en MRAMEGH., 27 (2017), p. 59.

${ }^{90} S A L$., Fondo Aguiló, Ms. 57, f. 23.

${ }^{91}$ Ibíd., f. 43.

${ }^{92}$ ARM., AH., 5953, I, f.1v.

${ }^{93}$ BRundage, James A., The medieval origins of legal profession, cit. (n. 54), p. 456.

${ }^{94}$ ARM., Suplicacions 33, f. 178; EO 11, f. 62v.

${ }^{95}$ ARM., EO., 12, f. 36v.

${ }^{96}$ Planas Rosselló, Antonio, Los asesores de los vegueres y el baile de Mallorca, en BSAL., 58 (2002), pp. 75-92.

${ }^{97}$ ARM., Suplicacions 54, f. 156. 
cargo de asesor del gobernador de Mallorca ${ }^{98}$, cuyo titular era entonces el doctor Martí Desbrull ${ }^{99}$, su antiguo escudero, que se había licenciado y doctorado en Bolonia en un solo día, el 11 de marzo de $1427^{100}$.

En el ámbito político, accedió en dos ocasiones a la máxima magistratura representativa de la ciudad y reino de Mallorca, como jurado por el estamento de ciudadanos, cargo de carácter anual que desempeñó en 1413 y 1417 . Su participación en ese colegio de seis notables no ha dejado noticias de interés, ya que no se han conservado las actas de aquellos años. Durante su primer mandato, el gobernador Pelay Uniç promulgó un importante texto normativo formulado por los jurados del reino e integrado por 73 capítulos que regularon principalmente el procedimiento civil, pero también algunas cuestiones de derecho procesal penal, notarial y civil sustantivo ${ }^{101}$. No podemos saber en qué medida fue responsable de la redacción del texto, pues consta que fue consultado con el abogado de la Universidad y otros doctores en leyes.

En todo caso, resulta revelador que Bernat fuese el primer miembro conocido de su familia que ocupó una dignidad que, a partir de entonces, recaería periódicamente en algunos de sus descendientes, comenzando por su hijo Rafael, también doctor en leyes. Una expresión evidente de la promoción social impulsada por su doctorado boloñés.

\section{Las donaciones piadosas y los servicios a la Iglesia de Bernat de Oleza}

Bernat de Oleza ha dejado así mismo su huella como benefactor de algunas instituciones eclesiásticas. Su padre, el ciudadano y mercader Jaume de Oleza, tuvo una gran implicación en las obras de la catedral de Mallorca, de cuya fábrica ocupó el cargo de administrador. A su muerte, a finales de 1414 o principios de 1415, el doctor en leyes le sucedió en el cargo ${ }^{102}$. En 1406 se había comprometido a aportar 50 florines para las obras del templo y, de hecho, en 1426 hizo efectiva una cuantiosa aportación para la construcción de una bóveda, a cambio de la cual se le permitió colocar en la clave un imponente medallón con sus armas,

${ }^{98}$ Pons Pastor, Antoni, Capitols per lo offici de sastres, en BSAL., 22 (1929), p. 369.

${ }^{99}$ Hijo de Joan Desbrull, maestro en medicina. En 1422 desempeñó una embajada ante la reina María junto al caballero Hugo de Sant Joan (Cód. 197, ff. 36-38). En julio de 1431 fue nombrado por Alfonso V lugarteniente del asesor del gobernador de Mallorca, Jimeno de Pueyo (LR 55, 244). En 1433 la reina María aceptó su renuncia del cargo y designó para sustituirle al doctor Joan de Copons (LR 56, 118). Fue consejero del Gran i General Consell en 1434 (CM, 156) y Jurado del reino en 1436. En 1439 fue nombrado miembro del Consell de la Franquesa por su condición de jurista (Llibre de n'Abelló, 77). Fue insaculado para concurrir a los cargos por el estamento de ciudadanos en 1447 (EO 14, 91v). En 1449 había fallecido. CanYELLES, Antoni, Tall per a una armada contra corsaris (1449), en BSAL., 24 (1933), p. 22.

${ }^{100}$ Sorbelli, Albano, Il "Liber secretus iuris Caesarei" dell'Università di Bologna, II, 1421 1450 (Bolonia, 1942), p. 64.

${ }^{101}$ Moll, Antoni, Ordinacions y sumari dels privilegis, consuetuts y bons usos del Regne de Mallorca (Mallorca, 1663) pp. 1-42.

${ }^{102}$ SASTRE Moll, Jaume, El finançament de les obres de la Seu de Mallorca, en De Computis. Revista Española de Historia de la Contabilidad, 12 (2010), p. 118. 
que todavía puede contemplarse ${ }^{103}$. También se le ha atribuido la financiación de un conjunto de cuatro ángeles tallados en piedra y dos en madera conservados en dicho templo, algunos de los cuales llevan pintadas las armas de Oleza. Sin embargo, no existen pruebas documentales que permitan descartar que se deban a la munificencia de otro miembro de su linaje, posiblemente su hijo Rafael ${ }^{104}$.

Los Oleza disponían desde antiguo de una sepultura en el claustro del convento de Santo Domingo, en la capilla de su antepasado Bernat Cerdà, en la que sabemos que fueron inhumados sus mayores, entre ellos su padre y su tío, el licenciado en leyes Berenguer ${ }^{105}$. Joan Domenge considera que hubo de ser Bernat el miembro de la familia Oleza que encargó para aquel convento un retablo dedicado a San Bernardo, San Antonio y San Nicolás, en el que se representa al donante en actitud de oración, a los pies del abad de Claraval. Lo mismo sugiere Tina Sabater, que data el retablo en el segundo decenio del siglo XV. ${ }^{106}$ De ser cierta la más que plausible hipótesis de ambos historiadores del Arte, se conserva en el Museo de Mallorca un retrato orante del jurista a los pies de su santo patrón.

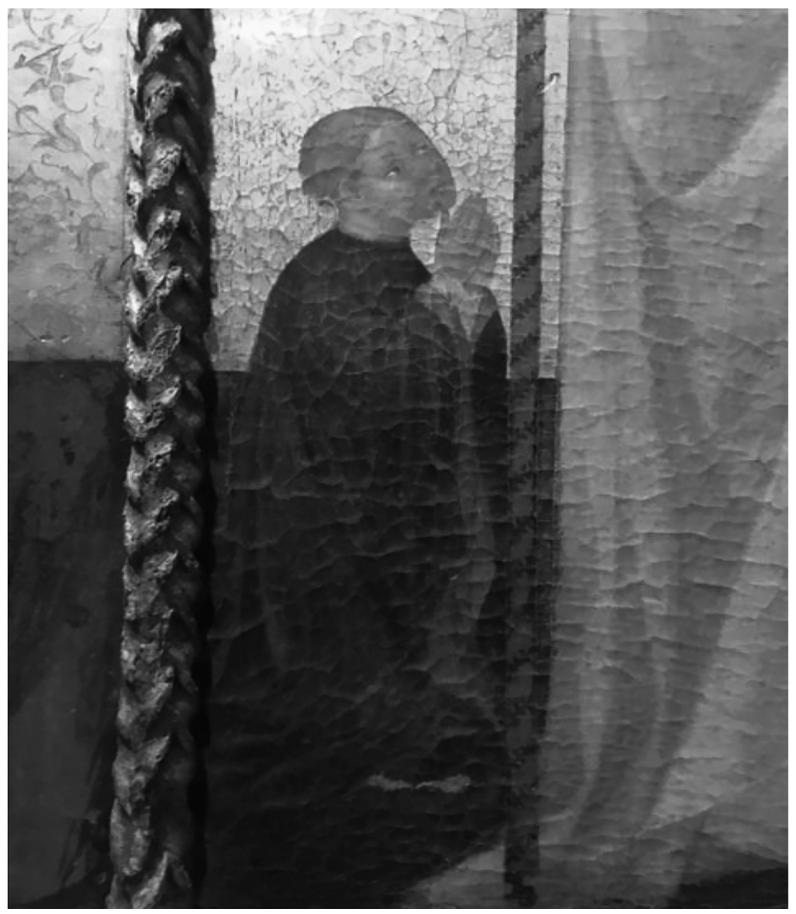

Retrato orante de Bernat de Oleza. Museo de Mallorca

${ }^{103}$ Domenge Mesquida, Joan, A laor de Déu e en remissió de pecats, cit. (n. 16), p. 508.

${ }^{104}$ Ibíd., p. 500.

${ }^{105}$ Así se afirma en el testamento de Pau de Oleza. Ibíd., p. 539).

${ }^{106}$ Sabater, Tina, Iniciativa privada i promoció de l'Art. Els retaules gòtics de Mallorca, en Mercados de lujo mercados del arte. El gusto de las élites mediterráneas en los siglos XIV y XV (Valencia, 2015), pp. 77-93. 
No fueron esas las únicas aportaciones y servicios de Bernat Oleza a las instituciones religiosas, pues sabemos que en enero de 1427 ejercía como administrador de la obrería de la capilla de Santa María de Lluc, en Escorca, un importante centro de peregrinación de la isla ${ }^{107}$.

\section{La posición eCONÓmica de Bernat de Oleza}

Las citadas donaciones revelan una opulenta posición económica, que hemos podido acreditar. El testamento de Bernat, que sabemos otorgado ante el notario Joan Mairac el 21 de agosto de 1432, no se ha conservado, y tampoco contamos con un registro de sus bienes. Sin embargo, conocemos parte de ellos porque en el inventario post mortem de su hijo Rafael, levantado en 1464, se identifican muchos bienes como procedentes de su herencia ${ }^{108}$.

Nos consta que poseía una valiosa casa, que daba nombre a la manzana en la que se hallaba ubicada, en la parroquia de Santa Eulàlia de la Ciudad. Era esta la casa principal de los Oleza, adquirida total o parcialmente por Jaume de Oleza el 10 de agosto de $1300^{109}$. Se trata de la misma que en 1336 se describía como situada en la manzana d'en Jaume d'Euleza (sic), en la que el entonces titular moraba junto a su madre ${ }^{110}$. En 1449, unos años después de la muerte de Bernat, habitaban en ella su hijo Rafael, y un nieto, hijo de su difunto hijo Jaume ${ }^{111}$. El 15 de agosto de 1432, poco antes de morir, Bernat había renunciado a sus derechos sobre otras casas en la calle de la Almudaina, que confrontaban con la suya y que su padre había establecido en enfiteusis a su primo Pau de Oleza, hijo del licenciado en leyes Berenguer ${ }^{112}$.

En cambio, pensamos que eran muy pocos los bienes rústicos de cuyo dominio útil disfrutaba. Las tierras que en 1367 poseían los Oleza en el valle de Bunyolíi13, habían dejado de pertenecer a la familia, como nos revela un documento de 1405 que se refiere al honor (el predio) que fue de Jaume de Oleza en ese valle ${ }^{114}$. El único bien que podemos afirmar con toda seguridad que poseyó es una viña en las afueras de la ciudad, que en 1345 era propiedad de su

${ }^{107}$ LlOMPaRT, Gabriel, La piedad medieval en la isla de Mallorca a través de nuevos documentos, en Analecta Sacra Tarraconensia, 51-52 (1978-1979), p. 257.

${ }^{108}$ ARM., Prot. M-190, ff. 148-174.

${ }^{109}$ En el inventario de bienes de Rafael de Oleza se destaca la escritura de compra de una casa en esa fecha, autorizada por el notario Miquel Rotlan (Prot. M-190, f. 169).

${ }^{110}$ Miralles Monserrat, Joan, Corpus d'antroponims mallorquins del segle XIV (Barcelona, 1997), p. 191. Este Jaume debe ser el mismo que en 1329 habitaba en la manzana de Guillem Andreu (Ibíd., p. 94).

${ }^{111}$ Canyelles, Antoni, Tall per a una armada, cit. (n. 99), p. 9.

${ }^{112}$ Rosselló Lliteras, Joan, Els pergamins de la Cartoixa, cit. (n. 1), p. 174. Esa casa sería adquirida luego por su hijo Rafael a los herederos del presbítero.

${ }^{113}$ En 1367 un esclavo turco de Jaime de Oleza hirió a su señor, domiciliado en la baronía de Bunyolí. Albertí, Jaume y Rosselló, Ramon, Història d'Esporles. Segles XIII-XVI (Palma, 1996), p. 147.

${ }^{114}$ Ibíd., p. 167. 
antecesor Jaume de Olesa ${ }^{115}$, y que puede identificarse con la que en 1460, tras la muerte de Bernat, pertenecía a su hijo Rafael ${ }^{116}$.

Lo más destacable de su situación económica es que, aparte de sus presumiblemente pingües ingresos profesionales, gozó de unas rentas muy cuantiosas. Algunas derivaban de los alodios de ciertas fincas cedidas en enfiteusis desde antiguo, pero su principal activo eran los títulos de deuda que poseía sobre la Gabela de la Sal, la Consignación de la Universidad de Mallorca y el Colegio de la Mercadería, y una inmensa cantidad de censales en dinero, trigo o aceite consignados sobre inmuebles urbanos poseídos por particulares de distintos estamentos ${ }^{117}$.

Ni Bernat ni sus hijos participaron en un fenómeno económico generalizado a lo largo del siglo XV, por el que las principales familias de caballeros y ciudadanos, entre ellos muchos doctores en leyes o cánones, hicieron cuantiosas adquisiciones de tierras en los municipios rurales de la isla ${ }^{118}$. Por el contrario, parece que prefirieron invertir en activos más rentables a corto plazo o, como sabemos que hizo Rafael, en algunas tierras y viñas situadas en el término de la Ciudad, muy cercanas a la urbe.

\section{La muerte de Bernat de Oleza. Su descendencia}

Hemos documentado por última vez a Bernat con vida el 27 de agosto de $1432^{119}$. Seguramente se hallaba entonces aquejado de alguna dolencia, pues seis días antes, como ya sabemos, había dispuesto su testamento y, en instrumento aparte, había renunciado a los derechos que poseía sobre la casa de su primo Pau. Su muerte se debió producir poco más tarde. En un pleito iniciado por sus herederos en los primeros meses de 1434 se indica que hacía algún tiempo que había fallecido ${ }^{120}$. Su edad debía ser de unos 56 años.

Bernat estuvo casado con Sibila Pont i Pax, de ilustre familia de origen mercantil, con la que tuvo al menos dos hijos varones, Jaume y Rafel, el segundo de los cuales siguió los estudios de leyes. A pesar de que la familia Oleza fue objeto de un importante estudio de su descendiente José de Oleza y de España publicado en 1973, su genealogía medieval no se ha podido desentrañar completamente. El Archivo familiar utilizado por el autor, que actualmente se halla depositado en el Archivo del Reino de Mallorca, carece de la documentación

${ }^{115}$ LlOMPART, Gabriel, Notas sueltas sobre viajes y viajeros mallorquines a Canarias (Siglo XIV), en Anuario de Estudios Atlánticos, 30 (1984), p. 390.

${ }^{116}$ Villalonga Morell, José y Fernández Legido, Roberto, El terme de Palma. Evolució de la propietat i l'espai (Palma, 2018), II, p. 289.

${ }^{117}$ La relación ocupa 28 páginas del inventario de Rafael. Muchos de ellos constan como adquiridos por Bernat. ARM., Prot. M-190, ff. 156-169.

${ }^{118}$ En la exhaustiva relación de compraventas publicada por José María de Quadrado, figura sólo la tardía compra del predio Talapi, en el municipio de La Pobla, que adquirió en 1480 Domingo de Oleza (1512†), uno de sus nietos. Quadrado, José María, Forenses y ciudadanos. Historia de las disensiones civiles de Mallorca en el siglo XV (2a ed., Palma, 1895), p. 318.

${ }^{119}$ ARM., Suplicacions 35, f. 2.

${ }^{120}$ SAL., Fondo Aguiló, Ms. 57. 
necesaria, como lo demuestra el hecho de que dos importantes documentos que transcribimos en apéndice se hayan localizado en otro fondo particular que, en principio, no tiene relación directa con la familia: Habent sua fata libelli. Por ello, no pudo establecer de forma inequívoca la filiación de las distintas generaciones de los siglos XIV y primera mitad del XV. Este hecho, unido a una acentuada homonimia ha provocado algunos enredos que tampoco nosotros podremos desentrañar completamente.

Sin embargo, sabemos que no se debe identificar a Jaume de Oleza Pont, hijo de Bernat, con otro Jaume de Oleza, estudiante de leyes en Italia en 1421, hijo del notario Joan de Oleza ${ }^{121}$, escribano de la Procuración Real de Mallorca. Según el historiador José de Oleza, el notario Joan era hijo del licenciado en leyes Berenguer ${ }^{122}$. Sin embargo, pensamos que se puede identificar con un Joan, menor de edad, hijo de otro Berenguer de Oleza, que en septiembre de 1371 había fallecido ${ }^{123}$.

Ese Jaume, studentis in iure civili, fue propietario de un códice que se conserva en Florencia, en el que se indica claramente que era hijo de Iohannes de Ol[es]ia, notarii maioricensis. Según un texto allí recogido, su madre tuvo que ser una dama de la familia Cupini, ya que se indica que el códice le fue entregado a Jaume por domina Johaneta, mujer de su avunculus, el honorable Iacobo Cupini ${ }^{124}$.

Así, podemos afirmar que los documentos mallorquines que mencionan en este periodo a un Jaume de Oleza con los títulos de in legibus bacalarius o iurisperitus, se refieren al hijo del notario Joan y no al homónimo hijo del doctor Bernat de Oleza. Este jurisperito estaba ya en Mallorca el 18 de agosto de 1425, cuando vendió una esclava al notario Ramon Almenara ${ }^{125}$. El 11 de mayo de 1433 nombró procurador al mercader Gerardo Guarandelli, de Montpellier, para que recuperase los bienes que había dejado en aquella ciudad -entre los que señala expresamente sus libros, joyas y plata- y que los enviase en un navío a la isla, a su riesgo y ventura ${ }^{126}$. Probablemente su estancia en esa urbe universitaria se debiera a una escala de su peregrinatio academica. El 1 de octubre de 1452 había fallecido, dejando una viuda de nombre Bárbara ${ }^{127}$. No hemos podido documentar la vida profesional de este Jaume, sin duda menoscabada por su carencia de la licenciatura o el doctorado, en una época en la que tales títulos

${ }^{121}$ Documentado como escribano en octubre de 1388. Rosselló Lliteras, Joan, Els pergamins de l'Arxiu parroquial de Santa Creu, (Palma, 1989), p. 168. Fue creado por Juan I notario real en toda la dominación del monarca y prestó juramento en Monzón el 3 de julio de 1389 (ACA., Real Cancillería, 2013, 25). Era escribano de la Procuración Real el 28 de abril de 1402. Rosselló Lliteras, Joan, Ibíd., p. 199. En 1421 ejercía como lugarteniente del Procurador Real durante su ausencia de la isla. SANCHO, Pere Antoni, El verdugo en Mallorca en 1421, en BSAL., 3 (1889), p. 306.

${ }^{122}$ Oleza y España, José, La Familia de Oleza, cit. (n. 2), p. 34.

${ }^{123}$ ARM., Prot. T-12, f. 137.

${ }^{124}$ LEVI, Ezio, El romance florentino, cit. (n. 78), pp. 44-47.

${ }^{125}$ ARM., Prot. O-2, f. 21v.

${ }^{126}$ ARM., Prot. S-25, f. 166v.

${ }^{127}$ ARM., Prot. G-90, f. 73v. 
comenzaban a ser inexcusables para ejercer en Mallorca ${ }^{128}$. Su memoria ha perdurado, en cambio, por haber copiado en aquel libro en blanco que le entregó su tía Joaneta, un importante conjunto de poemas en castellano y catalán, entre los que destaca el más antiguo manuscrito del conocido romance de la gentil dama, alterado con formas catalanas ${ }^{129}$.

Del hijo de Bernat, Jaime de Oleza y Pont, cives Maioricarum, es muy poco lo que hemos podido averiguar, salvo que casó en 1440 con Romia Rovira y Genovard, y falleció muy joven, poco antes del 2 de octubre de $1443^{130}$, dejando dos hijos párvulos: Bernat, que fue su heredero universal, e Isabel, casada con Felipe de Bordils ${ }^{131}$.

Mucho mejor conocido es su hermano Rafael de Oleza y Pont que, emulando a su difunto padre, se licenció y doctoró en Bolonia el 17 de julio de $1437^{132}$. En 1440 se le documenta en Mallorca ejerciendo ya como Legum doctor ${ }^{133}$, y en 1447 fue insaculado para concurrir a los oficios judiciales y los cargos representativos que se cubrían anualmente mediante sorteo ${ }^{134}$. No llegó a ocupar ninguna de las plazas togadas, pero tuvo mayor suerte respecto a las magistraturas municipales, ya que fue Jurado del reino por el estamento de ciudadanos en 1451 y 1458, y en ambas ocasiones, en virtud de su formación jurídica, se le encomendaron importantes misiones ante la Corte. En junio de 1451 fue enviado a Nápoles como síndico del reino ante Alfonso el Magnánimo ${ }^{135}$, para darle cuenta de la situación de la isla durante la insurrección de los pobladores de las villas, y solicitarle que adoptase las medidas necesarias para restablecer el orden. En 1458 se desplazó a Barcelona como embajador del reino para jurar fidelidad al nuevo monarca, Juan II, y solicitarle la confirmación de las franquezas y privilegios ${ }^{136}$, que fue concedida por el rey el 13 de diciembre de ese año ${ }^{137}$, junto con otros

${ }^{128}$ De hecho, tras un exhaustivo análisis de la documentación, a lo largo del siglo XV solo hemos localizado tres jurisperitos que ejercieron algunos oficios jurídicos en la isla, frente a 54 doctores y 4 licenciados. Planas Rosselló, Antonio, Los juristas mallorquines del siglo XV, en MRAMEGH., 7 (1997), pp. 23-60.

${ }^{129}$ LeVI, Ezio, El romance florentino, cit. (n. 78), pp. 39-73; Oleza y España, J., La Familia de Oleza, cit. (n. 2), p. 45.

${ }^{130}$ En esta fecha su mujer, Romia, ya era viuda. La última vez que se documenta a Jaume con vida es el 2 de marzo de 1442. BARCELÓ CREspí, Maria, Romia Rovira i Genovard (1422?1460?) i l'entorn familiar, en MRAMEGH., 14 (2004), p. 28.

${ }^{131}$ Así se indica en el testamento de Romia, de 24 de abril de 1460. Llompart, Gabriel, Siluetas cuatrocentistas del lulismo mallorquin, en BSAL., 35 (1977), pp. 182-184.

${ }^{132}$ Según el Liber Secretus: Examinatus fuit in iure civili, presentatus per dominum Nicholaum de Ghislardis, dominum Nicholaum de Sanctis et me Baptistam de Sancto Petro. Multum eleganter et copiose recitavit et in omnibus se gessit mirabiliter. Fuit approbatus, nemine discrepante; et illico, finito examine, fecit publicam suam et conventum in eodem loco. Ego tradidi sibi insignia doctoralia. Sorbelli, Albano, Il "Liber secretus, II, cit. (n. 100), p. 62.

${ }^{133}$ ARM., LR., 59, f. 154.

${ }^{134}$ ARM., EO., 14, f. 91v.

${ }^{135}$ No sin vencer una protesta del brazo militar, que exigía que el enviado fuese un caballero. JuAN VidaL, José, El sistema de gobierno en el Reino de Mallorca (Siglos XV-XVII) (Palma, 1996), pp. 48-49.

${ }^{136}$ ARM., AGC., 7, f. 75.

${ }^{137} A C A$., Real Cancillería, Juan II, reg. 3422, ff. 59-60. 
nuevos privilegios datados hasta el día 2 de enero de $1459^{138}$. Se han conservado algunas de las cartas que envió a los magistrados regnícolas para informarles de sus gestiones en ambos $\operatorname{casos}^{139}$. Tales embajadas solían ser una ocasión propicia para obtener de la real persona mercedes particulares, pero no fue ese su caso.

En 1461 fue elegido mediante el sistema de insaculación para desempeñar el oficio de abogado de la Universidad y Reino de Mallorca ${ }^{140}$, pero renunció al cargo alegando que hacía años que había abandonado la abogacía y carecía de los libros jurídicos necesarios para su desempeño, ya que los había vendido ${ }^{141}$. La disculpa del doctor Oleza era cierta, pues en el inventario post mortem de sus bienes figuran sólo ocho libros, todos ellos de carácter religioso ${ }^{142}$. En 1462 fue uno de los redactores de la respuesta negativa del Gran $i$ General Consell a la carta de los diputados de Cataluña en la que instaban a la asamblea representativa del reino de Mallorca a unirse a su rebelión contra Juan II $^{143}$. Falleció dos años más tarde, el 27 de julio de $1464^{144}$.

Rafael de Oleza estuvo casado con Isabel Zanglada, hija de Mateu, cives y de Agneta $^{145}$, de la que tuvo tres hijos varones: Domingo, Jaume y Bernat. Ninguno de ellos siguió a la carrera de leyes ${ }^{146}$.

\section{El ABANDONO DE LOS ESTUdIOS JURÍdicos POR LOS OlEZA}

La ciencia jurídica medieval era un saber libresco, y los libros jurídicos marcaron sin duda el devenir profesional de la familia Oleza. Hemos visto a Bernat preocupado por adquirir libros y recuperar los que dejó empeñados en Bolonia, y a Rafael vendiendo los suyos -sin duda muchos de ellos heredados de su padre- en el momento en que decidió abandonar el ejercicio de su profesión. Los trató como costosos instrumentos laborales y no, por supuesto, como fuentes de cultura y saber contemplativo. Sin embargo, no pocos juristas, a la hora de dictar su testamento, se preocupaban por dejar sus libros a los hijos interesados en seguir su carrera. El doctor Bartomeu de Verí incluso llegó más lejos cuando dejó como usufructuario de su biblioteca a su yerno, el caballero

${ }^{138}$ ARM., Códice 2, Llibre d'en Sant Pere, ff. 160-162.

${ }^{139}$ ARM., AH., 6649 / 12. Las de la primera embajada están datadas entre el 11 de julio de 1451 (en Cagliari) y el 19 de octubre del mismo año en Nápoles. De la segunda, solo se conserva una carta enviada desde la ciudad condal el 4 de enero de 1459.

${ }^{140}$ Planas Rosselló, Antonio, El abogado de la ciudad y reino de Mallorca, BSAL., 57 (2001), pp. 61-82.

${ }^{141}$ ARM., Sort i sac $1, \mathrm{f} .15 \mathrm{v}$.

${ }^{142}$ Hillgarth, J. N., Readers and books, cit. (n. 74), p. 512.

${ }^{143}$ Piferrer, Pablo y Quadrado, José María, Islas Baleares (Barcelona, 1888), p. 281.

${ }^{144}$ Un mes más tarde, el 17 de agosto de ese año, se levantó el inventario post mortem de sus bienes (ARM., Prot. M-190, pp. 148-171).

${ }^{145}$ ARM., Prot. A-87, f. 112.

${ }^{146}$ Joaquín María Bover atribuye a Jaume y a Domingo haberse doctorado en jurisprudencia. Bover de Rosselló, J. M., Biblioteca de escritores Baleares (Palma, 1868), II, p. 11. Pero se trata de una noticia sin base alguna. Ni uno ni otro usaron jamás tales títulos, ni fueron insaculados para ejercer los oficios togados. 
y jurisperito Joanot de Sant Joan, con el encargo de que los pasase a aquéllos de sus nietos que quisieran estudiar leyes ${ }^{147}$. El caso de la herencia del doctor Bartomeu Armadans ofrece un ejemplo muy significativo de la importancia de ese legado. Este jurista, que falleció dejando varios hijos de corta edad, prohibió en su testamento la enajenación de su biblioteca, para propiciar que alguno de ellos siguiese la carrera de leyes. Sin embargo, el tutor de los impúberes consiguió que los tribunales dejasen sin efecto esta cláusula, en atención a que la herencia carecía de la liquidez necesaria para sufragar los gastos si mantenía ese capital inmovilizado. Así, la biblioteca fue enajenada y, tal vez por ello, ninguno de los hijos del doctor Armadans llegó a cursar los estudios ${ }^{148}$.

Estos ejemplos indican que la decisión de vender los libros que adoptó Rafael de Oleza no fue una simple consecuencia de su personal abandono de la toga, ni por supuesto de una necesidad económica que se desmiente por su extenso inventario de bienes y rentas. En realidad, vino a ser una determinación sobre el futuro social de la familia.

Así pues, la dinastía de los juristas Oleza se prolongó solamente durante tres generaciones, comenzando por un colateral, y no llegó a cumplir los cien años. Algo en absoluto inusual, ya que fueron muy pocas las estirpes de juristas medievales que superaron esa cifra.

Son muchos los autores que consideran hijo de Jaume de Olesa y Romia (a veces la llaman Catalina) Rovira, y por tanto nieto de Bernat, a un Pere o Pere Bernat de Olesa, catedrático de medicina en Valencia, que suponen nacido en torno a 1460, diecisiete años después de la muerte de Jaume. Se trata sin duda de un error, que parece provenir de una obra de Joaquín Bover, publicada en $1838^{149}$. A nuestro juicio sería más probable que fuese hijo de Jaume de Oleza y Zanglada, de quien hablaremos luego, y por tanto nieto de Rafael y bisnieto de Bernat. Pero tampoco esta filiación está demostrada. En todo caso, este fue el último miembro de la familia Oleza que siguió estudios universitarios, aunque en un ámbito diferente al de sus antecesores. Cursó medicina en Pisa, Montpellier y Lérida, y una vez doctorado marchó a Valencia, donde ejerció como examinador de médicos, ocupó una cátedra de Principios de Medicina en 1514, y falleció en 1531. Unos años después de su muerte se dio a la imprenta su interesante obra Summa totius philosophie et medicinae, en la que hace una exposición de la filosofía natural, la biología y la medicina, partiendo de postulados atomistas ${ }^{150}$.

Las siguientes generaciones de Oleza se caracterizaron principalmente por sus inquietudes literarias ${ }^{151}$, que pudieron cultivar sin las servidumbres del ejercicio

${ }^{147}$ Barceló Crespí, María y Ensenyat Pujol, Gabriel, Els nous horitzons culturals a Mallorca a finals de l'Edat Mitjana (Palma, 2000), pp. 90-91.

${ }^{148}$ Planas Rosselló, Antonio, Los juristas mallorquines del siglo XV, en MRAMEG., 7 (1996), p. 24.

${ }^{149}$ Bover, Joaquín María, Memoria biográfica de los mallorquines que se han distinguido en la antigua y moderna literatura (Palma, 1838), pp. 230-231.

${ }^{150}$ Vid. Lopez Piñero, José María y García Sevilla, Jesús, Pere d'Oleza (Petrus Dolese) y su obra 'Summa totius Philosophiae et Medicinae', en Actas del III Congreso Nacional de Historia de la Medicina (Valencia, 1969), II, pp. 125-129.

${ }^{151}$ Véase Ensenyat Pujol, Gabriel, Els Olesa: una familia lletraferida de la ciutat de Mallorca 
profesional en el foro. En ese aspecto, estuvieron más ligados a las aficiones de su lejano pariente, el redactor del códice florentino, que a las de sus ancestros más directos.

Entre los muchos Oleza literatos, sobresalió Jaume de Oleza y Zanglada, hijo de Rafael y nieto de Bernat, notable poeta, autor de diversas obras literarias, religiosas o filosóficas, tanto en latín como en vulgar ${ }^{152}$. Su hijo, Francesc de Oleza y Sanmartí, hombre de armas y de letras, escribió una conocida Obra del menyspreu del Món en cobles ${ }^{153}$, y otros escritos anclados en una estética medieval, sobre los que no es nuestro propósito extendernos. El 24 de diciembre de 1538 Francesc recibió de Carlos $\mathrm{V}$ el privilegio de caballero, y al ceñirse el cíngulo militar, consolidó de forma inequívoca la posición de su linaje en el brazo noble del reino de Mallorca.

Los estudiantes de leyes o cánones mallorquines siguieron frecuentando el estudio de Bolonia hasta mediados del siglo XVII. Algunos oyeron varios cursos, para doctorarse en otras universidades, especialmente en la de Pisa, mientras que otros, tras su paso por Lérida, Salamanca, Ferrara, Pisa, Padua o Pavía, se graduaron finalmente en el Alma Mater por antonomasia ${ }^{154}$. A pesar de ello, no consta en los Rotuli que ninguno de ellos volviese a desempeñar un lectorado extraordinario boloñés, como lo hicieron en Pisa Cosme Font en 1521 y Jaume de Montanyans en $1528^{155}$.

En cambio, en 1574 las prensas boloñesas de Giovanni Rossi darían a luz sendas obras jurídicas del doctor Pere Moll, laureado en aquella ciudad el 31 de marzo del año anterior: un Responsum y un Tractatus ${ }^{156}$ que, aducidos como mérito, permitieron que en mayo de 1593 Felipe II otorgase a este hijo de notario el privilegio de caballero ${ }^{157}$.

(segles XIV-XVI), en El món urbà a la Corona d'Aragó del 1137 als decrets de Nova Planta (Barcelona, 2003), pp. 583-590.

${ }^{152}$ Oleza y España, José, La Familia de Oleza, cit. (n. 2), p. 45; Miralles de Imperial, Claudio, Tres poemas de Jaime de Oleza, en Boletín de la Real Academia de Buenas Letras de Barcelona, 21 (1948), pp. 175-179.

${ }^{153}$ OlezA, Francesc, Obra dels menyspreu del mon en cobles, feta per lo magnific mossen Francesch de Olesa, cavaller, estant molt trist per la mort de la virtuossísima muller sua, novament estampada (Mallorca, 1540).

${ }^{154}$ Hemos localizado un buen número de doctorados de los siglos XVI y XVII, merced al trabajo de GuerRINI, Maria Teresa, 'Qui voluerit in iure promoveri'. I laureati in diritto nello Studio di Bologna (1501-1796) (Bolonia, 2005).

${ }^{155}$ Verde, Armando F., Dottorati a Firenze e a Pisa 1505-1528, Xenia Medii Aevi Historiam illustrantiam oblata Thomae Kaeppeli (Roma, 1978), II, pp. 666 y 775.

${ }^{156}$ Planas Rosselló, Antonio, Los estudiantes mallorquines en Italia, cit. (n.71), p. 477.

${ }^{157}$ ARM., Pere Moll, 38 / 1. 


\section{APÉNDICE DOCUMENTAL}

Doc. 1

1398, septiembre, 9. Bolonia

Título de Doctor en Leyes por el Estudio de Bolonia a favor de Bernat de Oleza, hijo de Jaime, de Mallorca.

Archivo de Can Ribas de Pina, Fondo de Pergaminos Desmur, Perg. $1^{158}$.

[In] nomine domini nostri Iesu Christi

Humana conditio a sui primordio in lucem inerudita perveniens, si sapientie lumine illustratur, dignis et altis est laudibus illi quod gloriosum nomen habere merentur qui longa assiduitate, labore et instancia vigiliarum per arduum doctrine callem ambulantes ad perfectionem sui studii inclitam perexerunt, nam nullum fortius bellum militantium in virtute, in fortia die noctisque vadunt ad onerum prelia semper intenti, et nisi per accutissimum ingenium, per quod ignorantie calligo deponitur in montem discipline scandere non valemus, cuius discipline potissime fructus in gloria conquiescitur, que benemeritis, ut ad illam indocti ferveant, est tribuenda illustri preconio laudium.

Cum igitur honorabilis et sapiens vir dominus Bernardus Iacobi de Aulesia, de regno Maioricarum, quem scientia, moribus et virtutibus spetialis perrogativa sublimavit honoris, dudum insistens studio iuris civilis in civitate Bononie in qua vigens Studium generale, sic gratia favente divina, in iure profecerit antedicto quod ipse Dominus Bernardus, die decimo nono mensis julii proxime preteriti presentatus per egregios legum doctores Bononie scilicet dominum Franciscum de Ramponibus et dominum Bartolomeum de Saliceto coram eximio iuris utriusque doctore domino Gasparo de Caldarinis, comite palatino et milite bononiensis, in hac parte vicario reverendi viri domini Baldasare Cossa de Neapoli, decretorum doctoris, archidiaconus bononiensis nunc in remotis agentis, ad quem ratione archidiaconalis dignitatis quam obtinet in ecclesia antedicta hec et similia in Studio bononiense predicto habent et debent [...] plenarie expediri. Et suppositus ipse dominus Bernardus privato examini doctorum dicti Iuris Civilis Collegii Studii Bononiensis quos dictus vicarius, per privata examinatione [...] Bernardo in dicto iure faciendi, more solito, vocati et congregati, comissit et fecit ad hunc finem ut [...] Dominus Bernardus per dictos doctores reperiretur sufficientis [...] posset postmodum in illo licentia publica et doctoratus et honorem recipere et habere.

Idem quod dominus Bernardus sic huiusmodi dictorum doctorum privato examini suppositum, [...] in ipso examine in prefato iure legendo, repetendo, arguendo, argumenta ipsorum doctorum reassumenda et ea viriliter solvendo, quod post diligentem et arduam examinationem factam per ipsos doctores de eodem domino Bernardo in Iure prefato, fuit ipse dominus Bernardus ab

${ }^{158}$ El pergamino, que estuvo plegado, presenta algunos agujeros en su parte central, que impiden la transcripción íntegra de algunas líneas, aunque únicamente se trata de algunos formulismos no esenciales. 
omnibus dictis doctoribus unanimiter eorum nemine discrepante tanquam [...] merito approbatus.

Idcirco sapiens vir Dominus Jeronimus de Polonia, licenciatus in iure canonico, suffulctus in hac per auctoritate dicti domini Baldasare Cossa, per dictum dominum Gasparem, eius vicarium predictum, hic habito concordi consilio et assenssu doctorum dicti collegii ad hec presentium, quorum nomina inferius describuntur, [...] doctorum, nobilium, religiosorum, clericorum, scolarium, [...] multitudine [...] prefatum dominum Bernardum in ecclesia cathedrali Sancti Petri [...] cathedram personaliter [...] examinatum et in illo repertum idoneum, nominavit, denunciavit et publice declaravit dicti iuris civilis, ipsique domino Bernardo presenti et humiliter recipienti ut digno et benemerito et hac promotione dignissimo legendi, docendi, disputandi, terminandi, cathedram magistralem ascendendi, illamque regendi in dicto Iure Civili, et quoslibet alios actus in ipso Iure publice exercendi Bononie et ubique locorum, ut in [...] Iuris magister et doctor, plenam et liberam licentiam tribuit et concessit, et omnimodam facultatem. Receptis succesive per dictum dominum Bernardum a dictos domino Francisco et domino Bartolomeo, ipsius domini Bernardi doctoribus et magistris, precipuis insigniis solitis, scilicet a dicto domino Francischo libro clauso et aperto, et a prefato domino Bartholomeo anullo impositione et dispensatione, ac capiti ipsius domini Bernardi bireti seu doctoralis diadematis impositione, necnon ab utroque eorum in actibus antedictis pacis osculo cum benedictione magistrali subsecuto, ut ipse dominus Bernardus, sic omnibus insignitus et etiam coronatus, similiter in eterna patria coronetur per eum qui vivit et est benedictus in secula seculorum, Amen.

Acta fuerunt predicta Bononie in dicta ecclesia cathedrali, sub etiam apensione sigilli dicti domini archidiaconi, presentibus dominis doctoribus dicti collegii, quorum nomina sunt hec videlicet dominus Andreas de Bobus, prior dicti collegii, dominus Franciscus predictus, dominus Ugolinus de Scappis, dictus dominus Bartholomeus, dominus Nicolaus de Zapolino, dominus Hugolinus de Presbiteris, dominus Thomas de Sancto Johanne, dominus Johannes de Lapis, dominus Jeremias de Angelellis, dominus Johannes de Canitulo, Dominus Karolus de Zambecariis, dominus Nicolaus de Aldrovandis, dominus Nicolaus de Azoguidis, Dominus Bente de Bentevoglis, dominus Johannes de Sancta Agata et dominus Florianus de Sancto Petro, necnon presentes reverendis patribus domino Pino sermensis, dominus Nicolao corbamensis et dominus Johannes dragonariensis episcopis, domino Petro de Ancarano, iuris utriusque doctore, et aliis testibus ad premissa.

Sub anno a Nativitate Domini millessimo trecentesimo nonagesimo octavo, indictione sexta, die lune nono mensis septembris de mane, pontificatus domini nostri domini Bonifacii Pape nono, anno nono.

Ego Peregrinus quondam Johannes de Zambecariis, comes palatinus et civis bononiensis, publicus apostolica, imperiali et communis Bononie auctoritate notarius, ac etiam notarius ex indulto apostolico archidiaconi bononiensis, predictis omnibus interfui eaque rogatus scribere, diversis negotiis occupatus per alium scribi feci, ideoque hic me suscripsi et in testimonium premissorum signum meum apposui consuetum. 


\section{Doc. 2}

1399, diciembre, 30. Bolonia.

Nombramiento del doctor Bernat de Oleza elegido y diputado para impartir la lectura del Volumen Parvum en Estudio de Bolonia durante el plazo de un año, con un salario de 100 libras boloñesas.

Archivo de Can Ribas de Pina, Fondo de Pergaminos Desmur, Perg. 2.

Universis et singulis presentem publicam et patentem paginam inspecturis.

Notum sit et manifestum quod vir sapiens Dominus Bernardus de Olegia, legum doctor egregius, per venerandam universitatem dominorum scolarium Utriusque Iuris Studii Bononiensis, ob eius laudabilia merita et suarum consideratione virtutum, electus fuit et legitime deputatus, et per sapientes et honorabiles dominos Reformatores studii antedicti et alios pro offitio magnificorum dominorum Antianorum et honorabilium dominorum de collegiis ad dictum Studium reformandum deputatos solemniter confirmatus, et in rotulo dicti studii unacum aliis doctores Bononie legentibus, conscriptus ad legendum lecturam Voluminis pro uno anno feliciter inchoato in principio studii proxime elapsi et continuato tempore finiendo, cum salario librarum centum Bononie eidem domino Bernardo solvendarum per Commune Bononie, quarum prefato domino Bernardo fieri debent et exhigi bullete de dicto suo salario per notarium Bulletarum ad hec deputatum, iuxta formam Rotuli prelibati et consuetudinem aliam observatam.

In cuius rei et fidei testimonium, Ego Michael Comelini Johannes, publicus Imperiali et Comunis Bononie auctoritate notarius et nunc notarius prefatorum dominorum Reformatorum Studii, predicta publice scripsi. Sub anno a Nativitate Domini nostri Ihesu Xristi Millesimo trecentesimo nonagesimo nono, indictione septima die penultimo mensis decembris, pontificatus domini nostri domini Bonifacii divina permissione Pape noni.

Doc. 3

1403, febrero, 25. Mallorca.

Carta del doctor Bernat de Oleza al mercader Cristofano de Bartolo di Cenni da Barberino di Mugello.

Archivo de Prato, Fondo Datini, busta 1110, inserto 23, códice $127818^{159}$.

Memoriale Bernardi de Olesia, Legum doctoris de Maioricis

Domine Xristofore, rogo vos quantum possum nec valeo quatenus sitis memor cum, Deo duce, applicueritis in loco de Prato, quod intromitatis vos an dominus Chynolo de Guardinis, eiusdem loci de Prato, sit ibidem an vero ab hoc seculo migravit, uti per aliquos fuit mihi relatum, de quo, si ita sit,

${ }^{159}$ La carta presenta algunas roturas en el margen derecho, que impiden la transcripción íntegra de algunas de las últimas líneas. 
doleo in inmenssum. Et casu quod aduch vivat, ab eodem mihi ex parte ipsum deprecetis quod velit vobis tradere illos quinternos Lecture domini Bartholomei de Salisseto, legum doctoris, quos pro me scribi fecit Bononie, videlicet super nono libro Codicis et super quarto libro eiusdem voluminis, incipiendo a lege "Si sciens, etc" scituata in titulo ad Senatusconsultus Velleyanum usque ad finem dicti quarti libri, et etiam duos quinternos forme maioris inter quos est scripta repeticio 1. edita C. de Edendo, per dominum Baldum, et tractatus de reprobatione testium editus per dominum Bartolus. Et etiam unum quinternum propria manu mea scriptum in quo erat descripta quedam reppeticio per ipsum facta Bononie, et etiam unum librum per me facto cum foliis pergameneis in quo est tractatus de Iurisdictione et super materia Trinitatis et de multa alia, qui liber est meus proprius et ipsum dimisseram in posse domini Bartholomei de Salisseto pro pignore pecuniarum quas michi concedebat, quare si ipsum rehabuerit a dicto domino Bartholomeo, quod mei amore ipsum vobis restituat. Et vos, eidem domino Chinolo satisfaciatis in eo quod pro me bistraxit, quod puto ascendere ad plus ad decem ducatos seu florenorum de Florencia, nisi maluerit dictos decem ducatos compensare cum illis quinquaginta libris quas pro me habuit lecturam quam habebam Bononie et in qua tempore mei recessus ipsum substitui, attamen ubi dictam compensationem ipsi aut succesores nollent admitere, audacter solvatis eisdem dictos $\mathrm{X}$ duchatos seu modicum plus aut minus pro casu quod non venirent ad metam dictorum $\mathrm{X}$ duchatorum.

Et ubi dictus Chinolus esset vita functus, quod abssit, rogo vos quod predicta petatis a fratre suo aut eius cognato, dando eis dictos $\mathrm{X}$ ducatos per modum superius enarratum. Et ipsis habitis, rogo vos ut illico, cum primum comode poteritis, dictos quinternos et alia superius explicata [...] per primum navigium tute transmitatis, et subito dictam quantitatem tradam factori vestro qui [...]. [...] quinternos michi tradet, et etiam ministrabo de omnes expenssas per vos premissorum ocassionatas $[\ldots]$.

Et ubi non essent in dicto loco de Prato, si essent alibi et possent rehaberi per vos, rogo [...] quinternos et alia supradicta per modum supradictum haberetis. Et alia pro nunch vobis non com[issimus] [...] quod me recomendetis dicto domino Chinolo et tamquam fratri meo. Ubi si vivat necnon etiam eius fratris ac etiam eius cognato et sorori. Et ubi cum predictis non valeretis informari puto quod domino Marcello Ditrotssi de Florencia possetis informari.

Scripta Maioricis XXV februarii MCCCC tertio in Maioricis.

Quia in memoriali domini Guabrielis fuit facta mencio quod vos seu illum ad quem dictum memorialem seu litera dirrigeret, quod dominus Petrus Sabisbal pro me emeret de Bononie Lecturam domini Bartholi super Codice, et quod pro ea si [...] fuissent, traderetur dicto venerabilis Petro quindecim ducatos, immo rogo quod ultra predicta, de predictis XV ducatis michi faciatis servicium, et habita dicta Lectura, ipsam michi transmitatis cum aliis domini Gabrielis, per modum per ipsum vobis recomissum, quoniam ilico diem tradita fuerit dabimus dictos quindecim ducatos, seu valorem ipsorum, seu id quod nomine meo fuerit bistractum.

Data ut supra per misser Bernardo de Olesia antedictum. 


\section{Doc. 4}

1403 , s. d.

Carta del doctor Bernat de Oleza al mercader Cristofano de Bartolo di Cenni da Barberino di Mugello, en la que le encarga la compra, a través de su socio en Bolonia de ciertos libros jurídicos, para si y para el jurista Gabriel Cardona, al estudiante en leyes Pere Sabisbal. Si éste se halla ausente, deberá pagar el precio a Martín de Torres, estudiante catalán en el colegio de los españoles de aquella ciudad.

Archivo de Prato, Fondo Datini, busta 1110, inserto 23, códice 127819.

Memoriale librorum qui debent emi in Bononia pro domino Gabriele Cardona et Bernardo de Olesia.

Domine mei,

Scribatis si placet socio vestro Bononie commoranti, quod ubi venerabilis dominus Petrus Sabisbal, in legibus licenciatus vel studens, peteret ab ipso octoaginta bononinos auri vel inde circa pro emptione Lecture Bartholi super Digesto Novo, pro honorabilis domino Gabriele Cardona et pro miniando ipsam, quod ad eius voluntatis ilico sibi tradantur nomine dicti honorabilis Gabrielis Cardona, assessoris nobilis domini gubernatoris, et quod ipsa empta et miniata, incontinenti transmitatur vobis hinc dicto honorabili Gabrieli, hic vel Barchinone, si ibi fuerit, et sibi placuerit tradatis.

Item etiam ubi dictus Petrus Sabisbal peteret pro pretio unius Lectura Chyni quam ibi debet emere pro me Bernardo de Olesia usque ad quantitatem viginti quinque bononiorum auri vel inde circa, quod etiam sibi tradat ad eius libitum, et quod faciat sibi tradi dictam Lecturam domini Chyni, et quod ipsam vobis, ut citius poterit, remitat michi tradendam per vos.

Item certificetur per vos dictus socius vester quod si dictus Petrus Sa Bisbal recesserit de Bononia et dominus Martinus Martin de Torres, catalanus, studens et commorans in collegio Yspanorum Bononie, cui etiam diriguntur presentes littere, et honus etiam emendi predictos libros est per nos iniunctum in absentiam dicti Petri Sa Bisbal, peteret dictas pecunias causa emendi dictos libros, quod sibi traderet per modum superius contentum et ordinatum. 